\title{
Rancang Bangun dan Pengujian Tungku Peleburan Aluminium Berbahan Bakar Minyak Bekas
}

\author{
Budi Istana, Japri Lukman \\ Program Studi Teknik Mesin, Fakultas Teknik \\ Universitas Muhammadiyah Riau \\ E-mail:budiistana@umri.ac.id
}

\begin{abstract}
Abstrak
Peleburan logam merupakan suatu proses produksi dengan cara mencairkan logam hingga mencapai titik lebur kemudian dituang ke dalam rongga cetakan hingga menghasilkan bentuk geometri semirip produk akhirnya. Penelitian ini bertujuan untuk merancang, membuat dan menguji tungku peleburan aluminium berbahan bakar minyak bekas (Minyak Jelantah). Tungku peleburan logam yang dihasilkan berkapasitas peleburan $10 \mathrm{Kg}$ Aluminium. Dimensi luar tungku berbentuk silinder dengan diameter 36 $\mathrm{cm}$, tinggi $40 \mathrm{~cm}$ dan dimensi dalam diameter $30 \mathrm{~cm}$ dan tinggi $35 \mathrm{~cm}$. Dari hasil pengujian diperoleh waktu yang dibutuhkan untuk melebur $1 \mathrm{Kg}$ Aluminium adalah 25 menit pada temperature mencapai 701 ${ }^{o} \mathrm{C}$ dengan konsumsi bahan bakar sebanyak 1,48 Liter. Tungku ini diharapkan dapat menjadi sarana pembelajaran bagi mahasiswa dalam perkuliahan teknik pengecoran logam non ferro khususnya aluminium.
\end{abstract}

Kata Kunci : Tungku pengecoran logam, Aluminium Scrap, minyak jelantah.

\begin{abstract}
Metal smelting is a process of production by means of a metal melt until it reaches its melting point and then poured into a mold cavity to produce a geometrical form as closely as the final product. This research aims to design, build and test-fired aluminum melting furnace waste oil (Used Cooking Oil). The resulting metal melting furnace with a capacity of $10 \mathrm{Kg}$ Aluminum smelting. he outer dimensions of a cylindrical furnace with a diameter of $36 \mathrm{~cm}, 40 \mathrm{~cm}$ high and $30 \mathrm{~cm}$ dimensions in diameter and $35 \mathrm{~cm}$ high. From the test results obtained by the time required to melt $1 \mathrm{~kg}$ Aluminum is 25 minutes at a temperature of $701{ }^{\circ} \mathrm{C}$ with castings achieve fuel consumption of 1,48 liters. This furnace is expected to be a learning tool for students in the lecture non ferrous metal casting techniques, especially aluminum.
\end{abstract}

Keywords: Metal casting furnace, Aluminum scrap, used cooking oil

\section{Pendahuluan}

Tungku peleburan atau disebut juga dengan tungku pengecoran logam memiliki banyak jenis dan metode pembakaran. Ada beberapa jenis tungku peleburan aluminium yang telah dikembangkan diantaranya tungku berbahan bakar gas yang dibuat oleh Magga (2010) yaitu dengan mengembangkan analisis perancangan tungku peleburan logam non-ferro jenis portable berbahan bakar arang sebagai sarana pembelajaran. Tungku peleburan yang direncanakan berbentuk kotak dengan diameter dalam berbentuk selinder dan cawan pelebur berbentuk selinder,dimensi tungku adalah $50 \mathrm{~cm} \times 50 \mathrm{~cm}$, diameter dalam selinder 30 $\mathrm{cm}$. Dari hasil analisis yang telah dilakukan diketahui bahwa besarnya kalor yang digunakan untuk melebur $5 \mathrm{~kg}$ aluminium diperlukan kalor sebesar 3.030.600 J. Volume dari cawan pelebur yang diperlukan adalah 1,5 liter. Pada 2011, Sundari juga telah mengembangkan tungku atau dapur. Dapur yang dirancang adalah dapur crucible berbahan bakar gas LPG berbentuk silinder dengan diameter $220 \mathrm{~mm}$ dan tinggi $300 \mathrm{~mm}$ dengan kapasitas $30 \mathrm{~kg}$. Dari hasil uji coba yang dilakukan diketahui bahwa untuk melebur aluminium scrap seberat30 kg diperlukan waktu 1 jam 37 menitdan bahan bakar yang digunakan adalah $3,60 \mathrm{~kg}$.

Ashgi (2009) juga telah melakukan rancang bangun tungku peleburan aluminium berbahan bakar minyak dengan sistem aliran udara paksa. Dapur peleburan yang dirancang dibuat dari tatanan bata tahan api yang dilekatkan dengan campuran semen dan pasir tahan api. Dapur lebur 
mempunyai tinggi $62 \mathrm{~cm}$, diameter luar $57 \mathrm{~cm}$ dan, diameter dalam $31 \mathrm{~cm}$. Dari hasil pengujiannya diketahui peleburan $4 \mathrm{~kg}$ alumunium menggunakan bahan bakar solar diperlukan 5,8 liter dengan waktu peleburan 50-55 menit, sedangkan dengan menggunakan oli bekas diperlukan 6 liter, dan memerlukan waktu peleburan 60-65 menit.

Dalam penelitian ini akan dibuat dan diuji sebuah tungku peleburan aluminium berbahan bakar limbah minyak bekas (minyak jelantah), karena bahan bakar tersebut harganya lebih murah dan ketersediaannya cukup banyak atau dapat diperoleh dengan mudah dan murah sehingga diharapkan dapat menjadi sarana pembelajaran dan pengayaan bahan ajar teknik pengecoran logam.

Aluminium merupakan logam ringan yang mempunyai ketahanan korosi yang baik. Berat jenis alumunium adalah $2,643 \mathrm{~kg} / \mathrm{m} 3$ cukup ringan dibandingkan logam lain. Kekuatan alumunium yang berkisar 83 - 310 Mpa dapat melalui pengerjaan dingin atau pengerjaan panas (Surdia dkk, 1994). Di pasaran Alumunium ditemukan dalam bentuk kawat foil, lembaran, pelat dan profil. Semua paduan alumunium ini dapat mampu dibentuk, dimesin, dilas atau dipatri.

Proses peleburan adalah proses pencairan bahan (besi cor) dengan jalan dipanaskan di dalam sebuah dapur peleburan, setelah bahan mencair kemudian dituang ke dalam cetakan (Arifin, 1976). Pada proses peleburan alumunium digunakan dapur jenis crucible. Dapur crucible adalah dapur yang paling tua dan paling banyak digunakan. Dapur ini kontruksinya sangat sederhana dan menggunakan kedudukan tetap dimana pengambilan logam cair dilakukan dengan menggunakan ladle atau gayung. Dapur ini sangat fleksibel dan serbaguna untuk peleburan dengan skala kecil dan sedang.

Terdapat tiga macam crucible menurut jenis bahan bakar: gas, minyak dan kokas. Dapur Crucible dengan bahan bakar kokas jarang digunakan karena kurang efisien.

Jumlah panas/kalor yang diperlukan dalam peleburan aluminium dapat digambarkan sebagai berikut (Zemansky, 1994) :

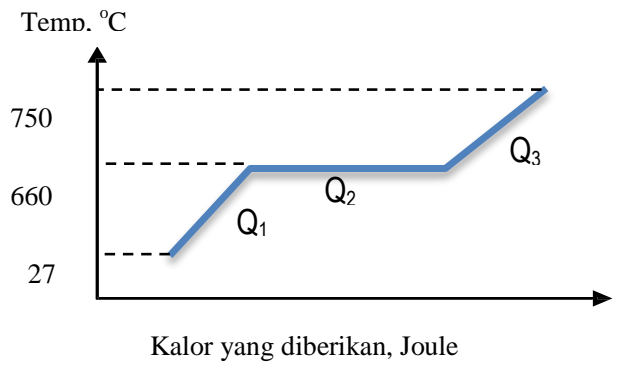

Gambar 1. Tahap peleburan aluminium
Kalor yang diperlukan dalam peleburan aluminium adalah :

$$
\begin{aligned}
\text { Qlebur } & =\mathrm{Q} 1+\mathrm{Q} 2+\mathrm{Q} 3 \\
& =\mathrm{m} \cdot(\mathrm{Cp} \cdot \Delta \mathrm{T} 1+\mathrm{KL}+\mathrm{Cp} \Delta \mathrm{T} 2)
\end{aligned}
$$

dengan,

Q1= kalor untuk menaikkan suhu kamar menjadi suhu cair aluminium

Q2 = kalor untuk mencairkan aluminium

$\mathrm{Q} 3$ = kalor untuk menaikkan suhu (aluminium dari $660{ }^{0} \mathrm{C}$ sampai $750{ }^{\circ} \mathrm{C}$ )

$\mathrm{m}=$ massa benda $(\mathrm{Kg})$

$\mathrm{Cp}=$ kalor jenis bahan (aluminium 8,8 $\mathrm{x} 102$ $\mathrm{J} / \mathrm{Kg} . \mathrm{K})$

$\mathrm{KL}=$ kalor lebur aluminium

$\Delta \mathrm{T}_{1}=$ perubahan suhu dari $\mathrm{T}_{1}$ ke $\mathrm{T}_{2} \quad \Delta \mathrm{T}_{2}$

$=$ perubahan suhu dari $\mathrm{T} 2 \mathrm{ke} \mathrm{T} 3 \mathrm{~T} 1$

$=$ suhu awal $\left({ }^{0} \mathrm{C}\right)$

$\mathrm{T} 2=\operatorname{suhu} \operatorname{akhir}\left({ }^{0} \mathrm{C}\right)$

Waktu yang diperlukan untuk melebur aluminium dapat dihitung dengan persamaan :

$$
t=\frac{Q_{\text {Lebur }}}{q_{\text {Cawan }}}
$$

dengan,

Qlebur = kalor yang diperlukan untuk melebur aluminium

qcawan = laju aliran kalor yang diserap oleh cawan/kowi pelebur

\section{Methodologi}

Gambaran umum penelitian ini dapat dilihat seperti diagram alir di bawah ini:

\subsection{Tempat dan Waktu Penelitian}

Penelitian ini dilakukan di Laboratorium Proses Produksi Fakultas Teknik Universitas Muhammadiyah Riau.

\subsection{Alat dan Bahan}

Peralatan yang digunakan dalam penelitian ini adalah:

1. Blower

Adalah alat yang digunakan untuk memberikan tekanan udara sehingga bahan bakar minyak bekas dapat terbakar didalam burner.

\section{Burner}

Adalah alat yang digunakan sebagai mediapencampuran bahan bakar minyak bekas dengan udara sehingga dihasilkan busur api yang 
bias dimanfaatkan sebagai sumber pemanas tungku peleburan.

\section{Mesin Las}

Adalah alat yang digunakan untuk membuat kedudukan tungku dan burner.

4. Mesin roll plat

Mesin yang digunakan untuk menggulung plat membentuk dinding tungku yang direncanakan berbentuk silinder.

Bahan yang dipergunakan dalam penelitian ini sebagai berikut:

1. Semen Tahan Api SK-32

Adalah semen yang berfungsi sebagai isolator untuk pembuatan tungku peleburan dengan ketahanan panas mencapai $1600^{\circ} \mathrm{C}$

2. Besi Siku

Adalah bahan yang digunakan untuk membuat kaki kedudukan tungku.

3. Pipa Besi 2"

Adalah bahan yang digunakan untuk pembuatan tempat lubang burnerminyak bekas pada tungku.

4. Minyak Bekas (Minyak Jelantah)

Adalah bahan yang digunakan sebagai bahan bakar dalam proses peleburan

\subsection{Rancang Bangun Tungku}

Rancang bangun tungku meliputi langkahlangkah:

1. Membuat gambar rancangan konstruksi tungku

2. Menentukan alat dan bahan untuk fabrikasi dan pengujian tungku

3. Fabrikasi tungku

\subsection{Pengujian Tungku}

Pengujian tungku peleburan dilakukan sebanyak tiga kali pengujian dengan menggunakan aluminium scrap sebagai bahan yang akan dilebur dan minyak jelantah sebagai bahan bakar. Adapun langkah-langkah pengujian tersebut sebagai berikut:

1. Ukur minyak jelantah dengan menggunakan gelas ukur kemudian tuang kedalam wadah penampung bahan bakar dan ditinggikan sekitar $180 \mathrm{~cm}$ dari dasar tungku

2. Atur posisi exhaust burner tepat pada lubang intake manifold tungku kemudian hubungkan intake burner dengan blower.

3. Masukkan sedikit arang yang sudah menyala pada burner sebagai pengumpan api lalu hidupkan blower.
4. Buka kran yang terdapat pada wadah penampung bahan bakar, pastikan bahan bakar mengalir lancar.

5. Setelah burner menghasilkan api yang sesuai, matikan blower lalu tempatkan kowi tepat ditengah-tengah tungku dan diisi dengan aluminium scrap yang telah ditimbang sebelumnya.

6. Nyalakan blower kembali dan proses pengukuran waktu dan temperature aluminium scrap yang ada didalam kowi dilakukan dengan menggunakan thermocouple digital.

7. Setelah aluminium melebur dan mencapai temperature diatas $700{ }^{\circ} \mathrm{C}$, kemudian dituang kedalam cetakan yang telah disediakan.

8. Sisa bahan bakar diukur kembali dengan gelas ukur untuk dianalisa lebih lanjut.

9. Pengujian kedua dan ketiga dilakukan dengan prosedur yang sama seperti pengujian pertama akan tetapi dilakukan ketika tungku dalam kondisi dingin.

\subsection{Analisis Data}

Analisis data yang dilakukan untuk menentukan:

1. Distribusi temperature terhadap waktu

2. Waktu peleburan

3. Laju konsumsi bahan bakar

\section{Hasil dan Pembahasan}

\subsection{Hasil Rancangan}

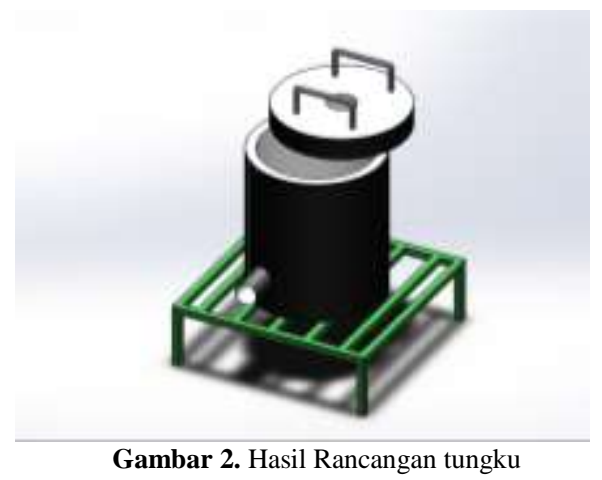

Hasil dari perancangan tungku pengecoran aluminium yang sudah dibuat memiliki tinggi $400 \mathrm{~mm}$ dan berdiameter luar $360 \mathrm{~mm}$. 


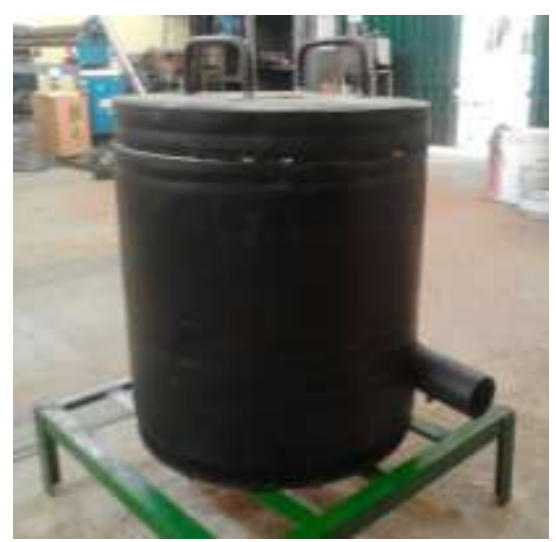

Gambar 3. Foto dokumentasi hasil rancangan tungku

Dinding dalam tungku dibuat dari bahan refractory yang mampu menahan panas hingga $1600{ }^{\circ} \mathrm{C}$

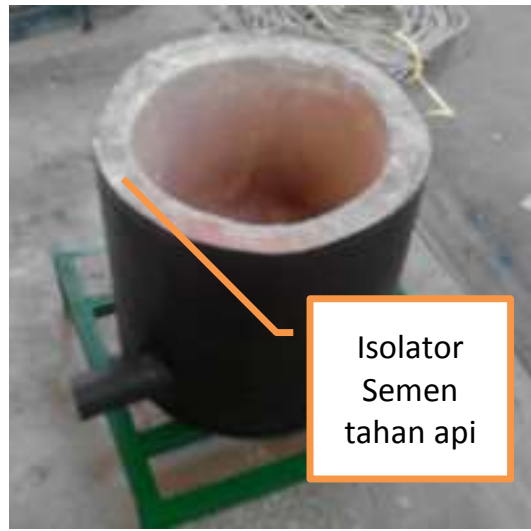

Gambar 4. Foto dokumentasi hasil rancangan tungku

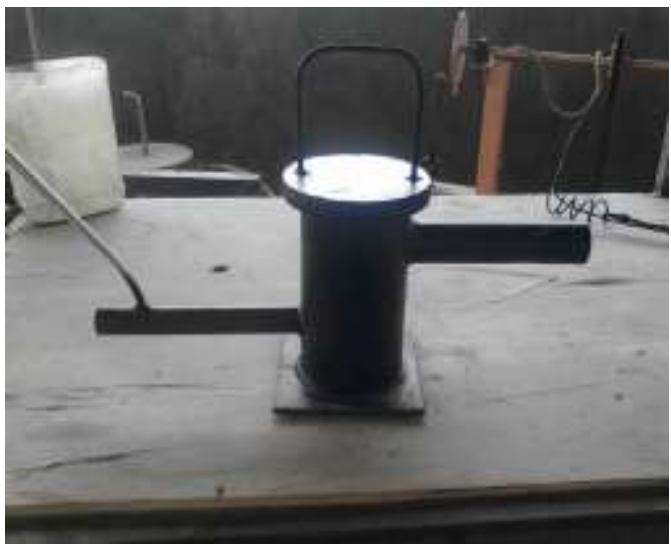

Gambar 5. Foto dokumentasi hasil rancangan burner

\subsection{Hasil Pengujian}

Pengujian dilakukan sebanyak tiga kali dan disetiap pengujian bahan bakar minyak jelantah yang disediakan senyak 3 liter dan jumlah aluminium sebanyak $1 \mathrm{Kg}$. pengujian kedua dan ketiga dilakukan ketika tungku sudah dipastikan dalam kondisi dingin $( \pm 24$ jam setelah pengujian sebelumnya). Data yang disajikan merupakan data rata-rata hasil pengujian.

Dari hasil pengukuran diperoleh distribusi temperatur terhadap waktu seperti ditunjukkan oleh grafik berikut ini:

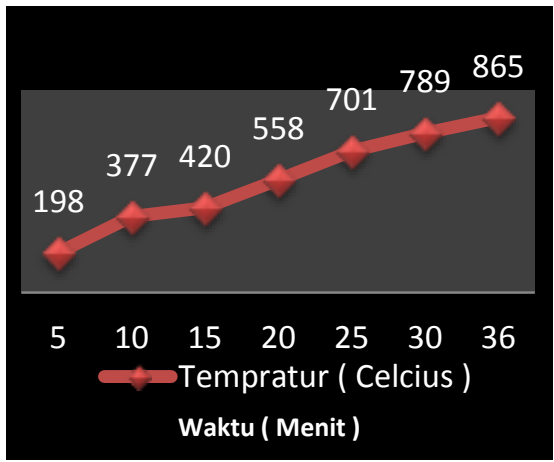

Gambar 6. Grafik distribusi temperature

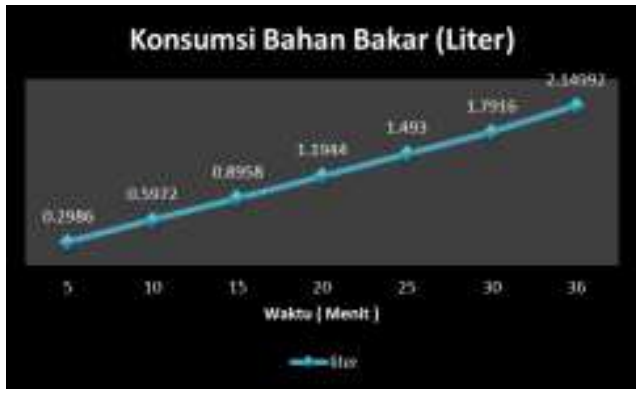

Gambar 7. Grafik konsumsi bahan bakar

Dari pelaksanaan pengujian, diperoleh data sebagai berikut:

1. Aluminium melebur pada temperatur $701{ }^{\circ} \mathrm{C}$ dalam waktu 25 menit.

2. Jumlah bahan bakar yang dibutuhkan sebanyak 1,493 liter.

3. Total aluminium yang dileburkan $1 \mathrm{~kg}+1 \mathrm{~kg}$ $+1 \mathrm{~kg}=3 \mathrm{Kg}$

\subsection{Pembahasan hasil pengujian}

Dari hasil pengujian tungku peleburan aluminium diketahui bahwa tungku yang dirancang mampu meleburkan aluminium scrap rata-rata 2,4 $\mathrm{Kg}$ per jam dengan laju pembakaran bahan bakar 3,6 liter per jam. Hal ini menunjukkan bahwa kebutuhan bahan bakar untuk melebur aluminium adalah sebesar 1,5 liter per kg aluminium scrap. Besarnya laju pembakaran bahan bakar ini sama dengan tungku peleburan berbahan bakar oli bekas yaitu 1,5 liter per $\mathrm{kg}$ aluminium scrap, Besarnya laju pembakaran bahan bakar lebih kecil jika dibandingkan dengan tungku peleburan berbahan

SURYA TEKNIKA Vol. 2 No. 4, Desember 2016 : 10 - 14 
bakar minyak tanah yang mencapai 1,6 liter per $\mathrm{kg}$ aluminium scrap dan lebih besar jika dibandingkan dengan tungku berbahan bakar solar yang mencapai 1,4 liter per $\mathrm{kg}$ aluminium.

Berdasarkan hasil pengamatan secara visual pada saat pengujian, sulitnya mengatur api burner masih menjadi kendala terbesar, hal ini disebabkan system feeding bahan bakar yang selalu tersumbat dan pengaturan bukaan kran bahan bakar yang belum tepat. Disamping itu, aliran udara dari blower juga tidak bisa diatur sehingga udara yang dibutuhkan tidak bisa di atur sesuai keinginan. Masih terdapat heat losses yang cukup tinggi terutama pada dinding luar tungku hal ini disebabkan kurang tebalnya dinding isolator.

\section{Simpulan}

\subsection{Simpulan}

Dari hasil pengujian dan analisis data yang telah dilakukan, maka dapat disimpulkan:

1. Tungku yang dirancang dapat digunakan untuk peleburan aluminium dengan laju peleburan 2,4 Kg per jam.

2. Laju konsumsi bahan bakar sebesar 3,6 liter bahan bakar perjam.

3. Besarnya laju pembakaran sama dengan tungku peleburan berbahan bakar oli bekas.

4. Besarnya laju pembakaran bahan bakar lebih kecil jika dibandingkan dengan tungku peleburan berbahan bakar minyak tanah

5. Besarnya laju pembakaran bahan bakar lebih besar jika dibandingkan dengan tungku berbahan bakar solar.

Besarnya kebutuhan bahan bakar untuk melakukan peleburan aluminium adalah sebesar 1,5 Liter bahan bakar per $\mathrm{kg}$ aluminium.

\subsection{Saran}

Penyempurnaan terhadap tungku peleburan hasil rancangan dapat dilakukan dengan melakukan perbaikan system pengumpan bahan bakar yang dilengkapi dengan alat penyaring, membuat blower yang bisa diatur kecepatannya serta memberikan lapisan isolator tambahan pada dinding luar tungku sehingga meminimalisir heat losess. Perlu pengujian lebih lanjut untuk mendapatkan hasil yang optimal dalam melakukan peleburan aluminium.

\section{Daftar Pustaka}

1. Zemansky, Sears, 1994, Fisika Untuk Universitas 1 : Mekanika, Panas, Bunyi, Binacipta, Bandung.
2. Arifin, Syamsul, 1976, Ilmu Logam, Jilid I, Ghalia Indonesia, Jakarta.

3. Ashgi, 2009, Rancang Bangun Dapur Kowi Pelebur Aluminium Berbahan Bakar Minyak, Digital Library, Universitas Sebelas Maret, Surakarta, http://digilib.uns.ac.id., diakses pada 05/04/2016, 15:16.

4. Holman, J.P. "Perpindahan Kalor", Erlangga, Jakarta, 1986.

5. Winarno, J., 2013, Rancang Bangun Tungku Peleburan Aluminium Berbahan Bakar Padat Dengan Sistem Aliran Udara Paksa, Jurusan Teknik Mesin Fakultas Teknik Universitas Janabadra Yogyakarta.

6. Magga, R., 2010, Analisis Perancangan Tungku Pengecoran Logam (non-Ferro) Sebagai Sarana Pembelajaran Teknik Pengecoran, JIMT Vol. 7, No. 1, Jurusan Teknik Mesin, Fakultas Teknik, Universitas Tadulako.

7. Sundari, E., 2011, Rancang Bangun Dapur Peleburan Aluminium Bahan Bakar Gas, Jurnal Austenit, Volume 3 Nomor 1, April 2011, Jurusan Teknik Mesin Politeknik Negeri Sriwijaya.

8. Tata surdia., Prof. Ir, M.Sc.Met dan Kenji Chijiiwa, Prof. Dr, 1982, Teknik pengecoranlogam, Jakarta. 